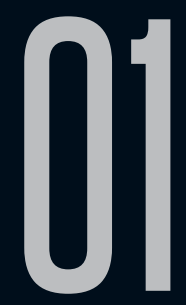

\title{
AS ARTES DO MAL (2018) DE JÚLIO FRANÇA E ANA PAULA ARAÚJO (ORGS.)
}

Isabela Duarte Britto Lopes (UFF)

Recebido em 07 abr 2020. Isabela Duarte Britto Lopes é Mestranda bolsista Aprovado em 17 mai 2020. em Literatura Inglesa pela Universidade Federal Fluminense (UFF). 
O livro organizado por Júlio França e Ana Paula Araújo é um compilado de textos-chave para pensar no Mal como um elemento estético, e não apenas como algo que se opõe à noção de Belo. As artes do Mal defende a ideia de que também há beleza no Horror e, para comprovar isso, apresenta 13 textos que discutem sobre como a literatura sombria e assustadora também é

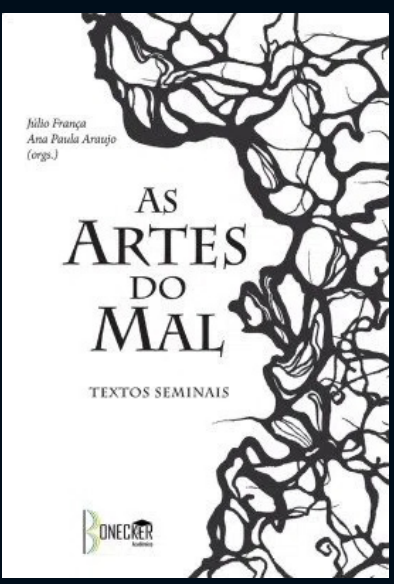
composta de um caráter artístico que merece destaque.

Por isso, os textos escolhidos para compor esta coletânea demonstram como o Mal pode despertar o leitor através das mais variadas reações, já que são capazes de causar sensações, ativar emoções e gerar experiências. E por que procurar por algo que cause tantos efeitos negativos? Esta é uma das perguntas que tais textos procuram abordar. Logo no prefácio da obra, percebe-se que este é um dos pontos que se tenta compreender com as leituras no decorrer do livro: "Buscam, enfim, respostas para a razão de sentirmos, simultaneamente, atração e repulsa pela violência, pela perversidade e por todo o tipo de ato cruel" (ARAÚJO; FRANÇA, 2018, p.13).

Ainda no prefácio, encontra-se um panorama geral sobre as discussões acerca do assunto, entre elas, as características que estão presentes nas obras que são frequentemente qualificadas como "más", as concepções divergentes sobre o conceito de Mal e também as diversas categorias em que este elemento pode ser concebido. Essas reflexões iniciais auxiliam o leitor através de sua 
"jornada profana" pelas leituras, questionando a função dessa literatura na sociedade e o papel que ela exerce para seus leitores.

O livro é dividido em quatro partes que abordam as representações do Mal de formas diferentes. A primeira, "Medo, terror, horror", lida com o medo na literatura e o prazer que advém das sensações causadas por leituras do gênero. A segunda parte, "O sublime terrível", trata do desconforto causado por algo que não é tangível e nem domável pela mente, isto é, aquilo que foge das explicações humanas e, por isso, é perturbador. Já na terceira, a vertente do Mal a ser trabalhada é o Gótico, de modo a abordar a relevância da atmosfera que as obras góticas criam e a sensação que essas construções provocam quando lidas. Por fim, a quarta e última seção se chama "Monstruosidades e perversidades" e discorre sobre a construção do monstro a partir da ideia de alteridade e daquilo que foge do que é considerado normal.

Antes de iniciar a leitura de cada trecho selecionado, o livro apresenta uma pequena bibliografia para apresentar o autor e dizer como e por que o escritor foi relevante para os estudos sobre o Mal. Além disso, já é introduzido o que o leitor deve esperar da obra, isto é, quais elementos serão analisados durante a leitura.

No primeiro texto, "XIII - Sobre o Medo", Montaigne discorre sobre situações históricas em que o medo estava presente e a reação dos homens perante uma situação de perigo. Neste caso, ele mostra como a mente humana pode reagir das mais diversas maneiras a essas situações extremas, seja com choque, histeria ou violência. O autor não procura definir a ideia de medo, e sim, refletir 
sobre os diferentes efeitos que esse sentimento pode causar. Para isso, ele exemplifica as consequências a que essa sensação remete, como no caso dos homens em guerra.

Como o trecho escolhido trata do medo em situações reais, ele não aborda a construção desse sentimento na literatura, mas aponta momentos em que essa emoção ganha forma e qual ela pode ser. Percebe-se que o instinto que nos alerta se estamos em uma situação de perigo pode desencadear respostas diferentes, já que o medo pode ser "ainda mais importuno e insuportável que a morte" (MONTAIGNE, 2018, p.27).

Já no segundo trecho que compõe a primeira seção, John Aikin e Anna Laetitia Barbauld discorrem sobre uma sensação comum ao contemplar cenas de horror criadas com fins artísticos: o prazer. Em um primeiro momento, parece contraditório dizer que o bem-estar pode ser associado a cenas assustadoras ou violentas, contudo, Aikin e Anna Laetitia ressaltam que nessas atividades de medo fabricadas pode-se praticar a empatia. Em outras palavras, o fato de o leitor se sentir incomodado com algo aterrorizante reforça a ideia de uma moral social que prova que aquele sujeito não é capaz de cometer atrocidades como as descritas ou representadas.

Além disso, outro aspecto que pode gerar essa sensação de prazer em um cenário de terror é a curiosidade, que impulsiona o leitor a buscar uma nova aventura ainda que de modo artificial. Esta instiga o leitor a desbravar um novo território que pode ser, ao mesmo tempo, fascinante e perturbador, o que acaba por unir a sensação de prazer com o medo. 
Aikin e Anna Laetitia acreditam que o terror do plano fantasioso pode ser mais prazeroso do que aquele mais próximo do real, sendo este, por sua vez, mais doloroso. O que não significa que não haja um sentimento positivo nas obras mais realistas, que é incitado em diferentes momentos, como ao terminar uma história e perceber que aquele cenário não reflete a vida cotidiana do leitor, causando uma sensação de alívio e conforto.

Já o terceiro e último texto dessa primeira seção conta com as reflexões de H. P. Lovecraft, famoso por suas obras fantásticas e assombrosas ao mesmo tempo. Em O horror sobrenatural na literatura, Lovecraft aponta que o maior medo do ser humano é aquilo que é desconhecido. Ao distanciar o leitor das respostas limitadas da vida cotidiana, o incógnito explora a sua imaginação e o distancia do ordinário.

Vale ressaltar que essas reflexões aparecem nas obras literárias de H. P. Lovecraft, já que o autor desbrava universos insólitos que transcendem as experiências mais conhecidas de medo. A incerteza presente no desconhecido representa a falta de respostas concretas e soluções e, por isso, é um perigo iminente que não há como combater. Lovecraft exemplifica esta ideia ao comentar sobre os weird tales e sua construção narrativa. Este gênero, que mistura aspectos sobrenaturais e científicos, cria uma atmosfera que gera desconforto e pavor para o leitor ao explorar as "leis fixadas pela Natureza" (LOVECRAFT, 2018, p.37).

A sensação de pavor e medo é o traço principal dos weird tales, pois, além de aterrorizar, as histórias são fascinantes e extraordinárias, direcionando o leitor a adentrar no caos do 
inexplicável e do inusitado. Por isso, Lovecraft aponta que para saber se uma determinada obra é weird, ou não, deve-se avaliar se ela desperta no leitor algum sentimento de pavor relacionado a um encontro com o desconhecido.

Ao contemplar os textos que compõem a primeira parte do livro, percebe-se que a relação que estes têm em comum é a discussão sobre o efeito que o medo pode causar no ser humano. Seja ele positivo ou negativo, artístico ou real, a questão é que este sentimento mexe com a mente humana e, ao mesmo tempo em que ele pode causar repulsa, ele também pode instigar, fascinar e ser prazeroso.

A segunda seção, "O sublime terrível", lida com o efeito do sublime, isto é, a contemplação do que causa estranhamento e ultrapassa as percepções da mente humana em relação ao mundo ao seu redor. Este elemento estético é uma ferramenta para a construção das sensações de pavor e desconforto fundamentais para as obras literárias que têm o medo como objetivo.

O primeiro nome a compor esta segunda parte é o de John Dennis, com trechos selecionados de Os fundamentos da crítica em poesia, em que o autor discorre sobre a importância das paixões na composição do que ele chama de uma "poesia elevada". Ele divide as paixões em duas categorias principais: vulgar e entusiasmada.

A paixão vulgar é aquela que pode ser concretizada por objetos e ideias que estão presentes no plano comum à sociedade, ou seja, aquilo que encontramos no mundo. Já a paixão entusiasmada, também chamada de entusiasmo, está relacionada com uma construção mental de algo que transcende 
a vida cotidiana, sendo, assim, a característica fundamental para a criação de uma poesia comovente ao público.

Dennis divide o entusiasmo em seis categorias principais, sendo elas admiração, terror, horror, alegria, tristeza e desejo. Ao realizar atividades de contemplação e meditação, essas paixões causam um efeito que altera o espírito do leitor a partir das imagens mentais que podem ser cunhadas, como no caso da poesia, em que um conjunto de representações abstratas desperta alguma dessas paixões.

O autor defende a ideia de que as imagens religiosas são a forma mais poderosa de despertar esses sentimentos em alguém. Isto pode ocorrer porque, quanto maior a imagem mental, maior seria a recepção e contemplação daquilo que é fascinante. Ao assumir as representações religiosas como a mais alta forma de expressar esses entusiasmos, acredito que não considerou que possíveis mudanças ocorreriam com o passar do tempo, haja vista que atualmente construções da própria realidade podem abalar o ser humano profundamente; contudo, é importante ressaltar que a visão de Dennis é um reflexo das ideologias do século XVIII que ainda tinham o Cristianismo como construção de verdades.

No que tange ao terror, Dennis acredita na grandiosidade desta paixão ao considerá-la horrível e admirável quando construída corretamente. Mais uma vez, ele utiliza como exemplo as ideias religiosas, pois acredita que esta é a maneira mais poderosa de fomentar ideias de terror na mente do leitor, como na imagem de um Deus enfurecido. 
Contudo, o aspecto principal a ser destacado nesse texto é a ideia de que quanto mais intensa a obra literária for, no sentido de instigar as paixões entusiasmadas, mais "elevada" ela seria, acompanhando os predicados artísticos de seu contexto cultural. Além disso, outro aspecto importante é a construção do terror a partir da sua grandiosidade e da ameaça que esta impõe ao leitor, que fica sem saber até onde o perigo pode atingi-lo de fato.

Já nos trechos selecionados de Edmund Burke, o autor desenvolve suas reflexões sobre dor e prazer, questionando a ideia de que um existe na falta do outro. Para isso, Burke diferencia a remoção da dor e o prazer positivo, e opõe também o prazer e o deleite. Além disso, ele mostra como tais sentimentos podem se resumir a uma impressão da mente em relação à sociedade ou à autopreservação, sendo comum lidar com os sentimentos de dor e perigo a partir desta última.

Para definir o que é sublime, esses sentimentos reaparecem, pois o autor acredita que tudo que seja capaz de produzir o terror é uma vertente do sublime, pois conseguiria ativar alguma emoção intensa na mente humana. Somando-se a isso, existe a ideia de que o deleite pode ser instigado pelo sublime, quando não ameaça o leitor diretamente, o que faz com que o terror também possa produzir sentimentos de prazer.

Outro aspecto importante discutido no texto é a paixão causada pelo sublime: o assombro. Esta paixão é tão intensa que é capaz de preencher a nossa mente e obscurecer a nossa razão - aquilo que é assombroso se torna um objeto de reverência e fascínio, ainda que relacionado ao horroroso. No mais, a 
obscuridade auxilia também na construção do sublime, pois permite que exista uma aura misteriosa e indecifrável que torna um determinado elemento assustador e incompreensível.

Os trechos escolhidos para a segunda seção reforçam a ideia do sublime como a elaboração de uma atmosfera estética capaz de estimular as paixões humanas. Para isso, várias sensações podem contribuir para que tal ambiente seja o mais aterrorizante possível, como a obscuridade, o assombro e até a fé na religião. Através destes, pode-se obter uma experiência literária que comova os leitores e incite sentimentos que só poderiam ser estimulados perante uma situação de perigo real.

A terceira seção foca na discussão sobre o gótico, entendendo-o como uma poética que explora os medos mais profundos do ser humano e o envolve em um clima de mistério e de elementos sobrenaturais, geralmente associados à morbidez, à melancolia e à morte. Para refletir sobre este tema, foram escolhidos não só textos críticos, mas também introduções de obras literárias consideradas clássicas do gótico.

A primeira discussão se inicia com o prefácio da primeira obra gótica publicada, $O$ castelo de Otranto, escrita por Horace Walpole. Neste romance, Walpole mistura aspectos sobrenaturais e reais ao mesmo tempo. Tal efeito acontece graças ao encontro do que o autor chama de atmosfera miraculosa com pessoas reais e suas reações ao choque do extraordinário.

O impacto gerado por este contraste de universos que se encontram faz com que a atenção do leitor esteja constantemente presa à leitura, estimulando emoções no decorrer de sua 
apreciação. Assim sendo, Walpole vê sua obra como uma narrativa que mistura realidade e misticismo, através da sobreposição do crível e do incrível. A imersão em um ambiente tão complexo gera dúvida e conflito, o que torna a obra fascinante, desconcertante e, principalmente, cativante para o público.

Já nos fragmentos escolhidos das obras de Nathan Drake, Sobre a superstição do gótico e Sobre objetos de terror, o autor trata do poder que a superstição tem para deter a atenção humana e como ela pode ser tanto algo desconfortante quanto um deleite. No gótico, a capacidade imaginativa do homem misturada com o mundo real cria uma nova possibilidade a ser explorada. Ainda que não seja provável, o autor acredita que o possível nos fornece novos caminhos a serem explorados, utilizando o nosso universo como um arcabouço desse fazer poético.

Drake também comenta sobre a origem dos objetos de terror e como eles podem derivar das ações sobrenaturais ou de eventos naturais. Para a construção de um terror proveniente de causas naturais, é necessário criar algo que possa gerar um deleite maior que a dor. O prazer e a curiosidade devem estar mais latentes no leitor do que a repugnância. Nesses elementos considerados objetos de terror, pode haver a presença do sublime, por ser um caminho para estimular a curiosidade do leitor sobre a obra.

Um outro nome de peso complementa as discussões sobre o gótico nesta terceira parte. Ann Radcliffe apresenta uma breve distinção entre terror e horror, sendo o primeiro um estimulante para as faculdades mentais e o segundo um inibidor delas, algo que as paralisa. Desta maneira, o terror permite que a criatividade 
do leitor preencha lacunas obscuras do texto, enquanto o horror gera apenas confusão e caos, não permitindo a utilização fértil da imaginação, apenas imagens borradas.

Apesar de o texto não esclarecer minuciosamente a diferença entre esses conceitos, Radcliffe apresenta os efeitos que estes criam no leitor, o que auxilia na compreensão dessas ideias em sua manifestação nas obras literárias. Além disso, a escritora ressalta a importância do autor para a obra e a percepção artística que este consegue retratar e transmitir para o seu público, através dos sentimentos evocados.

No último texto a integrar essa seção, Mary Shelley conta sobre o impulso criativo que a levou a escrever Frankenstein. $\mathrm{Na}$ introdução da terceira edição do romance, a autora relata um sonho que lhe causou tanto pavor, que fez com que ela se determinasse a escrever uma narrativa que pudesse causar sensação similar à que ela experimentou.

Nesse texto, ela também pondera sobre a relação do artista com a sua abominável obra, relação similar aos protagonistas do romance, Victor Frankenstein e o monstro criado pelo cientista. Entretanto, o que fica mais evidente neste trecho, é como o sentimento gerado em Shelley fez com que ela quisesse reproduzir essa sensação de alguma maneira, mostrando a relevância da capacidade que as obras góticas devem ter de estimular os nossos sentimentos mais fortes e profundos.

Desta maneira, os textos reunidos na terceira seção mostram como o gótico passa a integrar o fictício com elementos reais, intrigando o leitor ao fazer com que estes universos se encontrem 
em um lugar próximo de sua realidade. Por isso, o gótico é retratado pela sua atmosfera e, também, pelas sensações de conflito produzidas no leitor.

A quarta e última parte da coletânea busca refletir sobre os monstros como contraponto a tudo aquilo que é normal, compreendendo-os através da ideia de alteridade. Tudo aquilo que é estranho ou perverso representa uma ameaça ao modelo de vida "organizado" pelos padrões sociais, morais e culturais em que estamos inseridos. Entretanto, nem todo monstro precisa ter algum traço físico grotesco, basta ele ser capaz de cometer alguma atrocidade que ultrapasse os limites da humanidade.

A filosofia na alcova mostra como a perversidade existe como maneira de assegurar que o bem exista, ou seja, os atos libidinosos presentes no texto de Marquês de Sade são ações que equilibram a natureza por contrastar com a virtude. A destruição e a criação, o roubo e a riqueza, a religião e a libertinagem, todas essas oposições se completam, no sentido de que uma existe para reforçar a existência da outra.

Através desses fragmentos, fica evidente a existência do prazer no ato perverso, que no texto é representado pelo ato libidinoso. Tais corrupções devem ser concebidas como naturais, mesmo sendo contra os valores sociais pautados no Cristianismo que são trazidos à tona na discussão entre os personagens.

Já o texto de Edgar Allan Poe, que inicia o seu conto $O$ demônio da perversidade, mostra como a perversidade é uma característica inerente ao ser humano. É este aspecto que nos impulsiona a fazer o imoral, ou aquilo que não se deve, sem um motivo claro 
para isso. Em contraponto, há a combatividade que nos impede de realizar atos imprudentes, funcionando como uma sensação protetora e antagônica à perversidade.

O autor exemplifica como essas ideias funcionam através da imagem de uma pessoa à beira de um abismo. O que por um lado causa vertigem e medo, por outro lança a pergunta de como seria se jogar em queda livre. Poe argumenta que pensamos nessa possibilidade, não porque temos um desejo de morte, mas por sabermos que não devemos, ou seja, pelo simples desejo de sermos perversos.

No texto seguinte, é a vez de Charles Baudelaire apresentar suas reflexões sobre a perversidade. Em O pintor da vida moderna, acredita-se que a construção do belo é fabricada e tem um apelo estético artificial, enquanto a natureza seria apenas aquilo de que necessitamos. Pensando nisso, a moda seria a representação concreta deste fascínio pelo que é desnecessário, mas que é considerado agradável.

Para contrastar com essa visão do belo, Baudelaire descreve um prostíbulo onde tudo parece ser exagerado, sejam os movimentos, as maquiagens ou as interações. Ao utilizar este cenário, fica claro que as prostitutas são uma representação excessiva da artificialidade presente na moda, e o que as torna preciosas são os pensamentos obscuros e maldosos que possuem.

As comparações utilizadas para descrever as prostitutas, como o olhar do demônio, reforçam a concepção dessas mulheres como profanas e meros objetos de prazer público. Apesar da visão misógina, a obra analisa a beleza do Mal quando ela está 
presente de maneira mais oculta, não apenas na corporificação física da artificialidade.

O monstro, obra de J. K. Huysmans, encerra a discussão da última seção e do livro como um todo. Neste momento, apontase como os monstros perderam a capacidade de amedrontar e se tornaram ultrapassados. Se antes o monstro de Frankenstein causava arrepios, hoje ele já não nos impressiona mais. Agora a imagem do medo é representada pelo mundo real - um exemplo seriam os serial killers, pessoas capazes de cometer atos monstruosos e que não possuem nada de sobrenatural.

Por isso, o monstro, que se tornou caricato, dá lugar ao homem como seu próprio predador. O que atormenta não é mais o fictício e, sim, o real. Teme-se aquele que é consumido pela luxúria e pelo perverso e, por isso, se torna capaz de causar o Mal. A grande questão é que agora fica difícil separar o real e o imaginário, já que os monstros não são meras possibilidades da imaginação, uma vez que o novo monstro pode ser qualquer pessoa ao nosso redor.

A obra As artes do Mal faz um apanhado de conceitos elementares para entender o Mal como um efeito estético. Seja pelo sublime, pelo gótico ou pelo monstro, as representações do medo e do horror podem ser construídas através dos mais diversos recursos literários. Comprova-se também como a sensação de perigo e mistério pode estar atrelada ao prazer e à apreciação curiosa daquilo que foge a compreensão mundana.

Sendo assim, os textos que integram esta coletânea possibilitam uma reflexão inicial que fomenta outras possíveis análises críticas de textos literários e teóricos sobre o assunto. 
Por serem textos-base e seminais, eles são apenas o início de uma semente plantada, que agora já é apreciada por tantos outros estudiosos do meio acadêmico. Esta semente do Mal hoje se perpetua no livro de França e Araújo e permite que muitos outros contemplem as tantas faces ocultas que o sombrio e o aterrorizante nos reservam.

\section{REFERÊNCIAS}

FRANÇA, Júlio; ARAUJO, Ana. (Orgs.) (2018). As artes do Mal. Rio de Janeiro: Bonecker.

MONTAIGNE, Michel (2018). "XVIII - Sobre o medo". In: FRANÇA, Júlio; ARAUJO, Ana. (Orgs.). As artes do Mal. Rio de Janeiro: Bonecker.

LOVECRAFT. H. P. (2018) "O horror sobrenatural na literatura (Introdução)". In: FRANÇA, Júlio; ARAUJO, Ana. (Orgs.). As artes do Mal. Rio de Janeiro: Bonecker. 